\title{
The Analysis on Evolvement of Spatial Pattern of Economy at County Level in Guangdong Province
}

\author{
Pengzhen Shen, Weijin Gong \\ School of Economics, Jinan University, Guangzhou, China \\ Email: smx0117@163.com
}

Received 4 November 2015; accepted 24 November 2015; published 27 November 2015

Copyright (C) 2015 by authors and Scientific Research Publishing Inc.

This work is licensed under the Creative Commons Attribution International License (CC BY). http://creativecommons.org/licenses/by/4.0/

\section{(c) (i) Open Access}

\begin{abstract}
By selecting the per capita GDP of every county, this article uses the methods of exploratory spatial data analysis, Kiging spatial interpolation, semivariogram function, and the software of ArcGIS 10.0, Geoda and SPSS to show the spatial-temporal evolution of economic disparities at county level in Guangdong province from 1991 to 2013. The results show that: the economy of Guangdong province at county level presents a positive autocorrelation. It appears a downward trend in 2004, but it goes on growing at a steady trend. Cold-spot areas are dispersed in the north of Guangdong Province and the individual counties of East and West wings, while the hot-spot areas are mainly concentrated in the Pearl River Delta Center. Through the analysis of semivariogram function, it finds that the spatial self-organization of the county economy of Guangdong Province is getting stronger and the spatial random component of different pattern is in the smaller proportion. The main factors are due to the difference of natural conditions in regional economy, geographical conditions and regional development policy.
\end{abstract}

\section{Keywords}

The Disparities of County Economy, Spatial Autocorrelation, Semivariogram Function, Guangdong Province

\section{Introduction}

County economy is the basic unit of the national economy of the region. It is an important part of national economic development. Since the reform and opening up policy, the development of county economy is also grow- 
ing. Meanwhile, the unbalanced development of county economy becomes more prominent, and the regional economic differences of the county as the research unit are more prominent. Therefore, analyzing county economic differences and exploring spatial association of the county economy development and its evolutional pattern are of great significance for coordinating development of regional economy. From the existing literature, domestic scholars' studying on economic differences in China are gradually from the eastern, central and western of China, and then among provinces and city regions to transit the study of county-level differences. The foreign scholars are mainly from a macro level to study the regional economic differences of China. Rozelle [1] used the decomposition of Gini Index to study Chinese economic disparities and found that regional economic disparities between the southeast coastal provinces had expanded significantly between 1984 and 1989. Max. L [2] studied Chinese provincial economic differences between 1978 and 1990, then found that economic differences began to expand after 1990. Xu Jianhua and Lu Feng [3] were from the spatial and temporal scales with Theil coefficient decomposition method to analyze regional differences in China, and they thought that the Chinese Regional economic disparities from a large time scale basic obeyed the curve law of inverted "U" shaped. The study in recent years on the county economy is gradually increasing. Zhang Yi [4] had a research on the variation of county economic development in China according to the statistics from 1980 to 2008. The result showed that the variation of county economic differences in China was huge and had a tendency to extend continuously. Wang Yu et al. [5] had a research on the economic differences of 60 counties in Yangtze River Delta Area during the 1998 and 2009. Jin Cheng and Lu Yuqi [6] by explored the spatial changes of county economical spatial pattern in Jiangsu Province by the analytical method of ESDA. Meng Deyou and Lu Yuqi [7] studied about the county economic difference in Henan based on the data of per capital GDP in Henan Province during the 2000 and 2009.

As the first pilot of Chinese reform and opening up policy in Guangdong province, more than 30 years of reform and opening-up, at the time of rapid development of economy is obtained. The regional economic difference is also relatively large. Ouyang Nanjiang [8] had studied the changes of economic difference in Guangdong province since the reform and opening up, concluded that the economic differences of Guangdong province since 1980 to 1990 reform and opening up were expanded rapidly, mainly shown in economic differences of the Pearl River delta with other regions. Ding Song et al. [9] studied the county economy of Guangdong province from 1995 to 2010, and found that the county economic difference had narrowing trend as a whole during this period. Although there has research on county economic analysis of Guangdong province, but there was little quantitative research on the influence of the randomness and the structural factors of county economic differences of Guangdong province. Therefore, this paper, under the support of GeoDa, ArcGIS 10.0 and SPSS software, with 88 counties in Guangdong province as the research sample, combined the spatial autocorrelation and spatial variation function, with the per capita GDP of counties in Guangdong province and per capita GDP growth index from 1991 to 2013 as the research objective and adopted the quantitative analysis method for detailed analysis on the spatial and temporal evolution of the regional economic difference of the pearl river delta and the east, north, west region of Guangdong.

\section{The Research Region Definition and Data Sources}

\subsection{Research Unit and Data Sources}

According to administrative map of Guangdong province ${ }^{1}$ in 2005, this paper takes Guangdong province county region as the basic research unit, and defines county regions to a total 88 basic administrative units including administrative unit at the county level (county, county-level city, autonomous county), ground-level urban district or below (urban district at the same prefecture-level as a research unit, no more segment) and prefecture-level city without jurisdiction of county. Based on the availability of data, this paper selects the 1991-2013 years as a time quantum. Basic research index is the per capita GDP of the county region, the attribute data of county region is derived from Guangdong statistical yearbook among 1992-2014, several years of county region values are calculated according to the rate of growth due to a lack of data. In addition, similar to traditional division method, this paper divides Guangdong province into four regions as Pearl River Delta and Eastern, Western and North of Guangdong according to the geographical distribution of various counties and the economic de-

\footnotetext{
${ }^{1}$ According to the administrative division in 2005 in Guangdong province, the province of Guangdong includes 21 prefecture-level cities, 23 county-level cities, 41 counties and 3 autonomous counties.
} 
velopment level of different regions².

\subsection{Research Method}

\subsubsection{Descriptions of Spatial Correlation}

The indicators of spatial correlation mainly include global spatial autocorrelation and local spatial autocorrelation. Global spatial autocorrelation is the description of its attribute values in the spatial characteristics of the whole region, the main measurement indexes are Global Moran's I index [10] and Geary's C [11], and other global spatial autocorrelation statistics to analyze the spatial correlation and spatial difference degree of the whole region, this paper mainly use Moran's I index to analyze, and its calculation formula is:

$$
I=\frac{n}{S_{0}} \cdot \frac{\sum_{i}^{n} \sum_{j=1}^{n} w_{i j}\left(x_{i}-\bar{x}\right)\left(x_{j}-\bar{x}\right)}{\sum_{i}^{n}\left(x_{i}-\bar{x}\right)^{2}}
$$

where: $x_{i}$ represents the measured value at ith spatial unit(position); $w_{i j}$ represents spatial weight matrix, is defined as spatial adjacent of 1 , non-adjacent of $0 ; S_{0}$ is the sum of all the elements of spatial weight matrix. Moran's $I$ index is explained as a correlation coefficient, and its range is $[-1,1]$. If Moran's $I$ is significant positive, it indicates positive correlation existing among regions, that is the county region units with the similar level of economic development (higher or lower) are significant agglomeration. Otherwise, if Moran's $I$ is significant negative, it indicates the economic development level of some county region unit has significant spatial difference with surrounding region. Only when Moran's $I$ closes to the expected value $-1 /(n-1)$, the measured values are independent of each other, and shows a random distribution in space.

While the statistics of global spatial autocorrelation only explains the average degree of difference among the regions and the surrounding regions, to fully reflect the variation trend of regional economic difference, and it needs to adopt local analysis method. This paper mainly uses Getis-ord $G_{i}^{*}$ statistics (Getis and ord, 1992) [10] for the cold and hot spot analysis of the regional economic differences. Its calculation formula is:

$$
G_{i}^{*}(d)=\sum_{j=1}^{n} w_{i j}(d) x_{j} / \sum_{j-1}^{n} x_{j}
$$

In order to facilitate comparison and analysis, further standardization on $G_{i}^{*}$ is required, that is:

$$
Z\left(G_{i}^{*}\right)=\frac{G_{I}^{*}-E\left(G_{I}^{*}\right)}{\sqrt{\operatorname{Var}\left(G_{i}^{*}\right)}}
$$

where, $x_{j}$ represents the measured value of spatial unit $j, w_{i j}(d)$ represents spatial weight matrix. $E\left(G_{i}^{*}\right)$ and $\operatorname{Var}\left(G_{i}^{*}\right)$ in formula (3) are mathematical expectation and variable coefficient of $G_{i}^{*}$ respectively. If $Z$ is positive and significant, it indicates the surrounding values of position $i$ is relative higher (Higher than the average), and belongs to high value spatial agglomeration (hot spot); otherwise, if $Z$ is negative and significant, it indicates the surrounding values of position $i$ is lower than the average, and belongs to low value spatial agglomeration (cold spot).

\subsubsection{The Index of Average Economic Growth}

To a certain extent, the proportion of per capita GDP growth reflects differences in the levels of economic development among regions, this paper standardizes the average annual growth rate of economic indicators of each county region unit in research region, and makes the growth rate comparable in different periods:

$$
S=\frac{G_{t_{2}}-G_{t_{1}}}{G_{t_{1}}\left(t_{2}-t_{1}\right)} \times 100
$$

\footnotetext{
${ }^{2}$ The province of Guangdong is divided into Pearl River Delta, East Guangdong, West Guangdong and North Guangdong according to the geographical distribution and the level of economic development. The Pearl River Delta is composed of 9 cities including Guangzhou, Shenzhen, Zhuhai, Foshan, Jiangmen, Dongguan, Zhongshan, Huizhou, and Zhaoqing; East Guangdong refers to 4 cities as follows: Shantou, Shanwei, Chaozhou and Jieyang; West Guangdong refers to 3 cities as follows: Zhanjiang, Maoming and Yangjiang; While the north Guangdong includes those 5 cities which are Shaoguan, Heyuan, Meizhou, Qingyuan and Yunfu.
} 
where, $S$ is the average growth index of per capita GDP, $G_{t_{1}}, G_{t_{2}}$ represent per capita GDP at time $t_{1}$ and $t_{2}$, respectively.

\subsubsection{Spatial Variation Function}

Spatial variation function is also called semivariogram function, which is the specific basic means to describe the randomness and constitutive property of regionalized variables, can reflect the characteristics of the spatial variation degree changing with the distance. Assume $x_{i}$ is a regionalized random variable, and satisfies intrinsic assumption and stationary hypothesis, $h$ is the spatial separation distance of two points. The measured value of $Z(x)$ at spatial position $x_{i}$ and $x_{i}+h$ are $Z\left(x_{i}\right)$ and $Z\left(x_{i}+h\right)[i=1,2, \cdots, N(h)]$, respectively. The calculation formula of variation function $r(h)$ as [12]:

$$
r(h)=\frac{1}{2 N(h)} \sum_{i=1}^{N(h)}\left[Z\left(x_{i}\right)-Z\left(x_{i}+h\right)\right]^{2}
$$

where, $N(h)$ is the sample capacity of separation distance of $h$. It can be proved to grow as half variation function in mathematical sense, and spatial autocorrelation reduced. Spatial variation function curve (Figure 1) is as follows:

In figure, $C_{0}$ is the nugget value, used to reflect the spatial heterogeneity caused by local randomness of variable; $C$ is the structural variance, representing variation caused by structural factor that is spatial heterogeneity caused by variable spatial autocorrelation; $C_{0}+C$ is partial sill, indicating the total variation including random variation and structural variation, the higher the value of partial sill, the higher degree of spatial heterogeneity it is. $a$ is the range. That is the function scope of spatial correlation when the semivariogram function up to partial is sill in a certain scale. When the separation distance of the variable measuring point is less than this value, the variable is proved to be spatial correlation, otherwise, no spatial correlation exists. In addition, $C_{0}$ reflects the amplitude of change, $C_{0} \rightarrow 0$ reflects the continuous change, the greater of $C_{0}$, the amplitude is larger, nugget coefficient $C_{0} /\left(C_{0}+C\right)$ reflects the degree of this change, it represents the ratio of structural variation in total variation, the bigger of this ratio shows the stronger of the structural variation, if the ratio is close to 0 , it indicates regionalized variable has a constant variation on the whole scale. The ratio is also reveals the degree of spatial correlation of the regionalized variables. According to the division standard of Gambardella, etc., when $C_{0} /\left(C_{0}+C\right)>0.75$, variable has strong spatial correlation; when $C_{0} /\left(C_{0}+C\right)>0.25$, the spatial correlation is weak, when $C_{0} /\left(C_{0}+C\right)$ is in the middle of both, it indicates medium spatial correlation [13].

The fourth parameter of semivariogram function is fractal dimension. The value is determined by the relation of semivariogram function $r(h)$ and the spacing distance $h$ :

$$
2 r(h)=h^{4-2 D}
$$

Fractal dimension $D$ is the slope in log-log linear regression equation. It represents the curvature of the variation

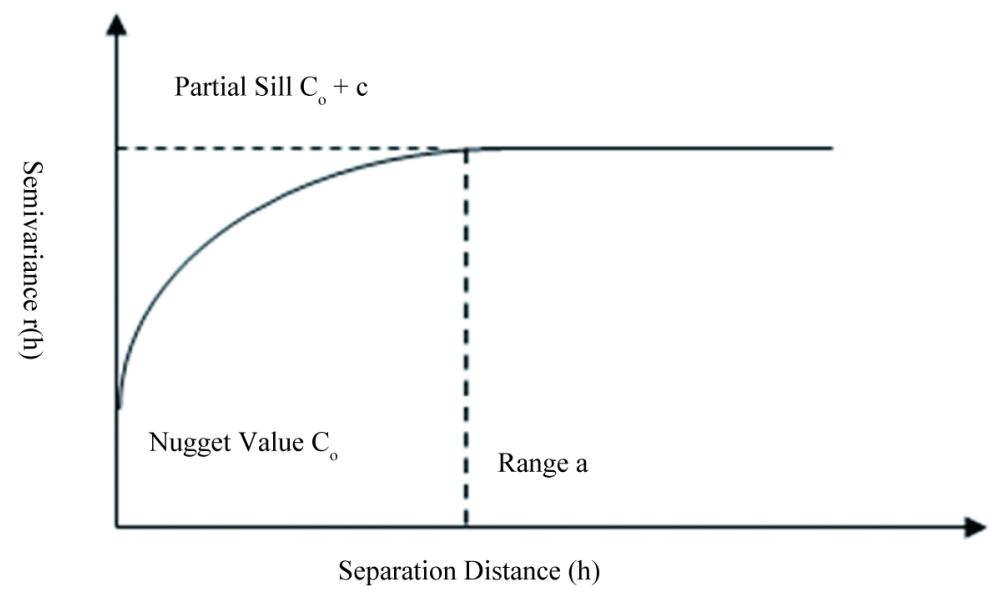

Figure 1. The cue of spatial variation function. 
function, and can be used as a measure of random variable. Using fractal dimension analysis, it can compare with the intensity of spatial autocorrelation among different variables, and its value is more close to 2 , the more balanced spatial distribution it is .In addition, the variation function is unknown in theory, it can be fitting with ArcGIS 10.0 related module by calculated values, the common fitting models are: Spherical model (Spherical), Exponential model (Exponential), Gaussian model (Gaussian) and Linear model (Linear) [14].

\section{Spatial Structure Evolvement of Regional Economy}

\subsection{Feature Analysis on General Spatial Pattern}

\section{Feature Analysis on Overall Evolution of County Economy in Guangdong}

According to relevant statistical indicators of per capital GD from 1991 to 2012, Global Moran's I index value of county and city area in Guangdong province each year is calculated by GeoDa and the Equation (1), and the trends are shown on Figure 2.

As can be seen from the figure, Global Moran's I of county-scale and urban economy in Guangdong province are positive and significant in the significance level of $1 \%$. This shows that since 1990, the spatial autocorrelation has existed both in the two levels of county-scale and urban economic development in Guangdong province. From the value-size of Global Moran's I of county-scale and urban economy, spatial aggregation of countyscale economy in Guangdong is stronger than urban economy, and namely, regional economic polarization in Guangdong has showed in county-scale economy. In addition, there has been an obvious difference in variation trend of spatial correlation in county-scale and urban economy since 2000. Spatial gathering of county-scale economy from 2003 to 2004 is decreasing, while urban economy has been an upward trend after 2000. One possible explanation is that: export-oriented economy of Guangdong in 2003 was being invaded by "SARS", and economic development had been severely hampered. County-scale economic gathering in Guangdong is weakened, and this trend has been reflected by Global Moran's I value of county-scale economy in Guangdong, while variation trend of urban economy has covered this phenomenon. Therefore, the study on county-scale economic difference in Guangdong in this article can reveal more specific varying pattern of the economy.

\subsection{The Analysis Figure of the County-Scale Economic Trend}

This paper selects four time sections of 1991, 1998, 2005 and 2013 for analysis, and depicts the trend analysis diagram of per capita GDP in counties of Guangdong at four time sections using ArcGIS 10.0 software, as shown in Figure 3.

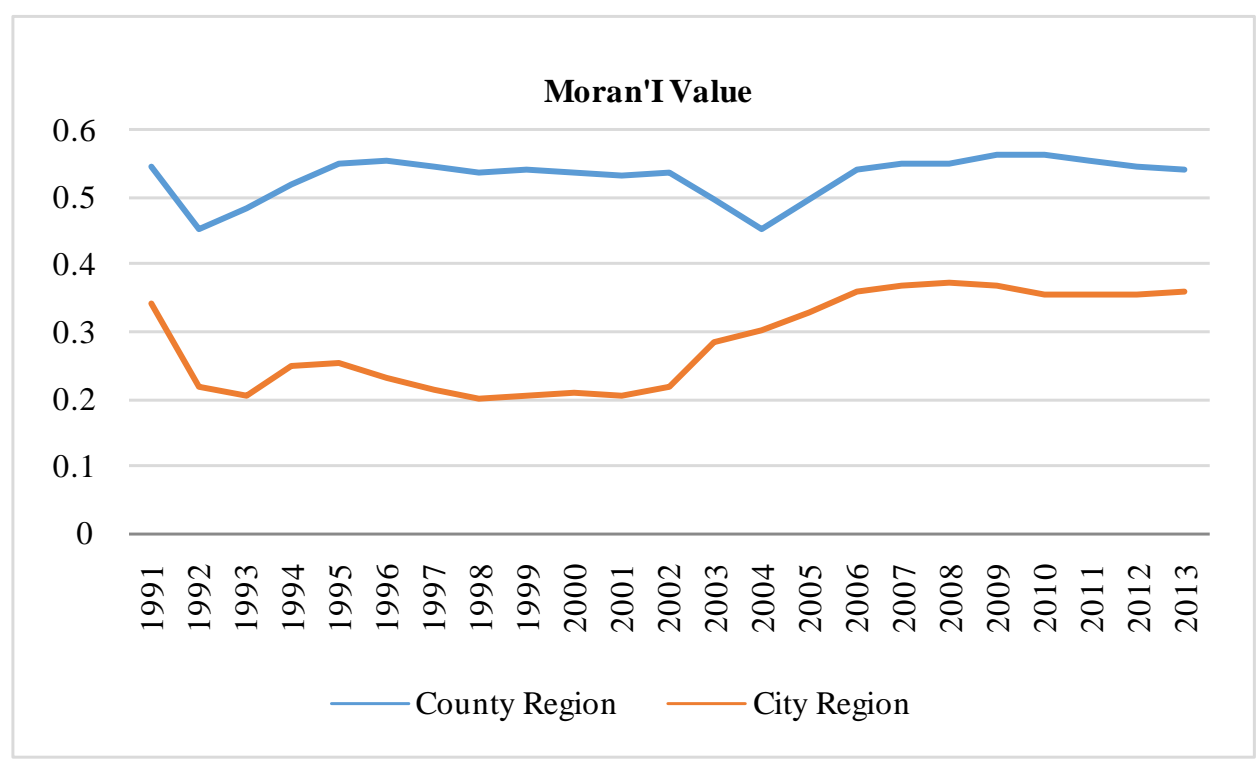

Figure 2. The trend graph of Moran's I value in global spatial autocorrelation of county-scale and urban economy in Guangdong province. 


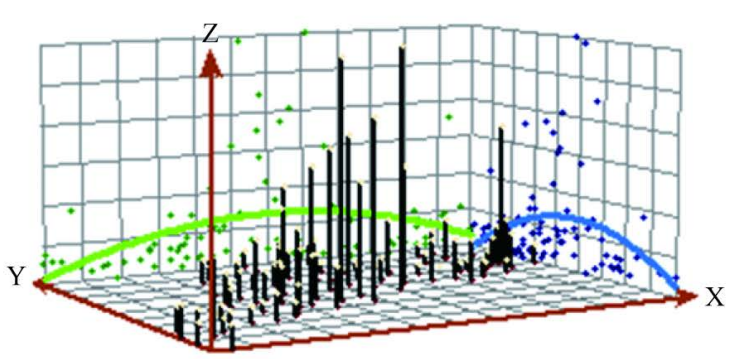

1991

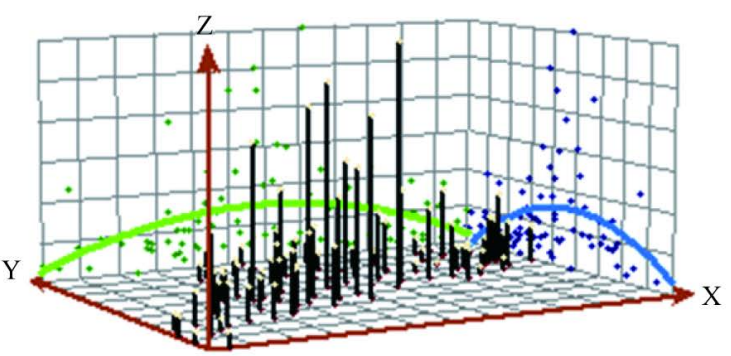

2005

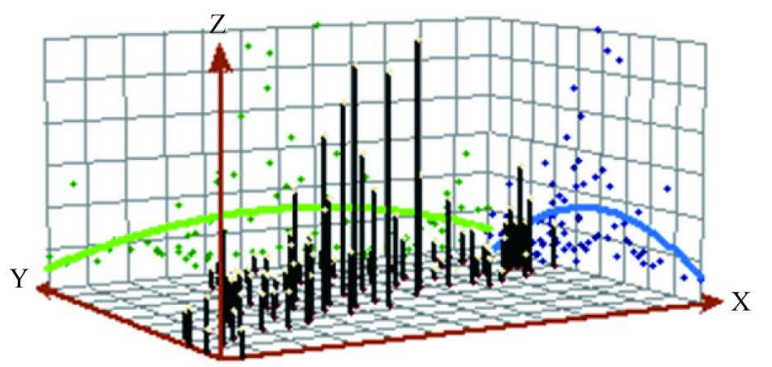

1998

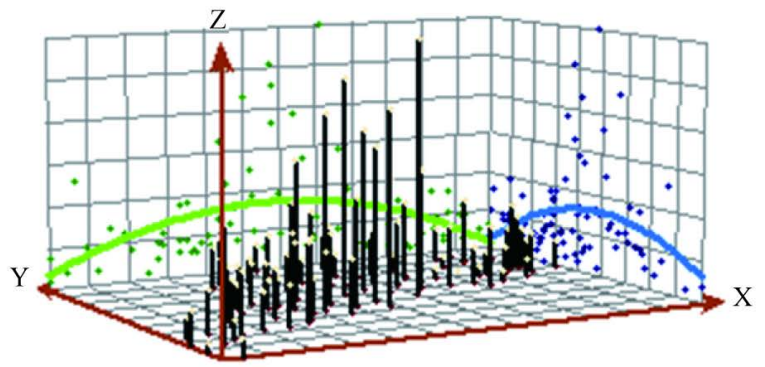

2013

Figure 3. County-scale economic tendency chart in Guangdong province.

Curve on YZ projection plane in tendency chart is the trend line in the north-south direction, and that on $\mathrm{XZ}$ plane is the trend line in east-west direction. As can be seen from Figure 3, in four time sections of 1991, 1998, 2005 and 2013, the measurements of counties in Guangdong province have showed an inverted U-shape in both directions of east-west and north-south, indicating that per capita GDP in both directions is low on both sides while high in the middle. On the whole, the ladder structure with central part as the vertex is formed.

\subsection{Spatial Structure Evolution of County-Scale Economic Hotspots}

To further understand the contribution rate of economy in counties to the global spatial autocorrelation as well as to explore evolution situation of the economic structure in Guangdong province in more detail, and taking four time sections as per capita GDP as variables, the paper calculates values of $G i^{*}$ and $Z$ according to the formulas of (2) and (3) and generates evolution diagram of spatial patterns of economic hotspots in Guangdong with ArcGIS 10.0, as shown in Figure 4.

As can be seen from the figure: firstly, although the whole spatial structure of economic hot spots in Guangdong has a certain degree of volatility from 1991 to 2012, there is a relatively small range of fluctuation. Hot spots are always in the Pearl River Delta region, which is namely the interior ring-shaped space structure with Guangzhou, Shenzhen and Dongguan, etc. as the core. It validates further that the Pearl River Delta region is the core area in economic development of Guangdong province and has greater contributions to the economic development. Eastern, western Guangdong and mountain areas of north Guangdong with larger areas are basically in low clusters, and spatial structure mainly focus on blocks, and economic development is in cold spots of Guangdong. So far, there has been no substantial change in the economic status of the cold spots of Guangdong province. Secondly, based on the evolution situation of the spatial pattern in hotspots, it can be seen that the Pearl River Delta region has played a role in radiation and driving and in spatial spillover effects for the economic growth in other areas. Compared with situation in 1991, municipal districts in Zhaoqing and Qingyuan have transformed from the secondary hotspot into the hot spot region in 2013 due to the radiation and driving function of the Pearl River Delta. Secondary hotspot has been located in the peripheral region of the center of the Pearl River Delta hotspot, and Conghua of Guangzhou and Qingxin of Qingyuan have evolved from secondary cold spot into secondary cold spot in 2013. Finally, part of the counties in the eastern, western and northwest Guangdong have also evolved from the spatial structure of the previous dispersed blocks into contiguous blocks. Among them, Zhanjiang and Maoming in the western Guangdong and part of the counties in Yangjiang have stepped into secondary cooling zone from cold spots, but some counties of Yunfu in the northern part of Guangdong have returned from secondary cold spot zone to cold spot area. 


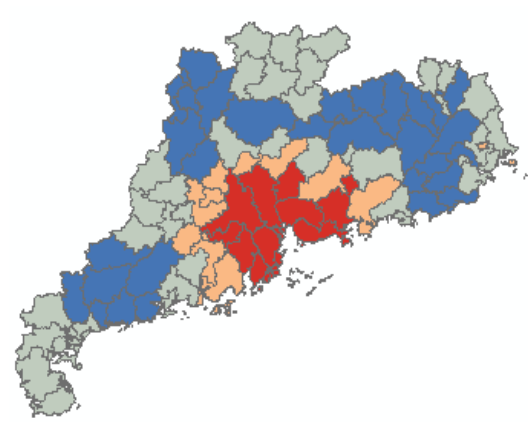

1991

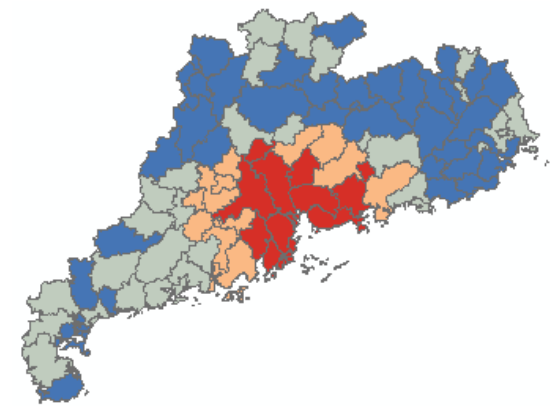

2005

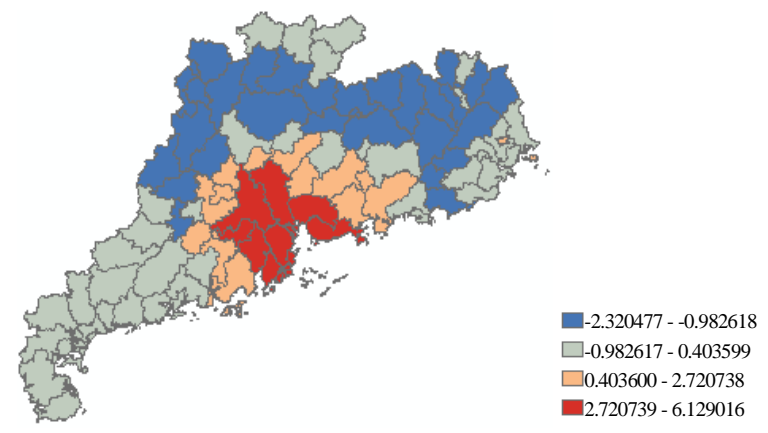

1998

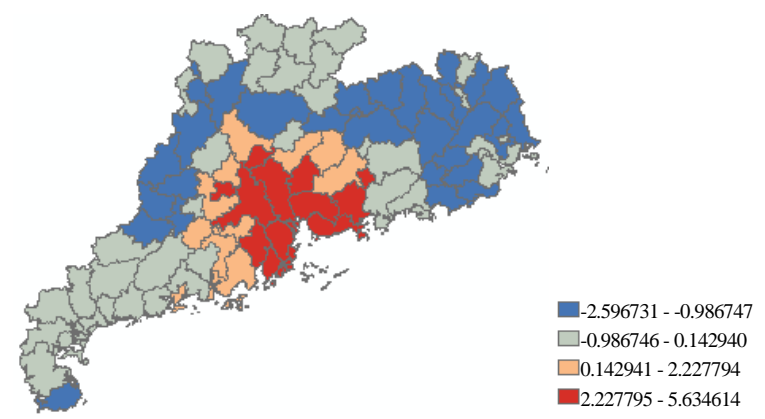

2013

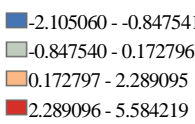

ㄷ.289096 - 5.584219

Coldspots $\square$ The Secondary Coldspots

Hotspots $\square$ The Secondary Hotspots

Figure 4. Evolution diagram of spatial structure of county-scale economic hotspots in Guangdong province.

\subsection{Analysis on Spatial Structure of County-Scale Economic Growth}

\subsubsection{The Spatial Pattern of per Capita Growth Index}

Analysis of spatial association every year can only measure spatial agglomeration of county-scale economy from a static point of view, while ignores the dynamic changes in the spatial pattern of economic growth. This paper has divided the study period into three sections of 1991-1998, 1998-2005 and 2005-2013, has calculated average economic growth index for each period according to the formula (4), and has made spatial correlation analysis using the Global Moran's I, and the results are shown in Table 1.

As can be seen from the table above: first of all, economic growth has significant spatial autocorrelation in three time periods. It is increased firstly and then decreased, with confidence coefficient greater than 95 percent. Therefore, in the three time periods, the county's economic growth in Guangdong is featured by spatial agglomeration, and namely, high-value areas are adjacent to the high-value areas, while low-value areas are adjacent to low-value area. Compared to two time periods of 1991-1998 and 2005-2013, spatial correlation from 1998-2005 is relatively strong, reflecting that the economic growth in this period has relatively strong accumulation pattern. Therefore, the agglomeration trend of spatial structure of county-scale economic growth in Guangdong has strong stability. Secondly, compared with the Moran's I indexes of per capita GDP in four years, Moran's $I$ in four years is significantly greater than the Moran's $I$ value of the increasing index in this period. Seen from agglomeration features, per capita GDP in four years has shown a tendency of down first and then up. The average economic growth index in three time periods has showed a tendency of up first and then down, indicating that the spatial pattern of county-scale economy in Guangdong province has shown a stronger momentum of gathering evolution in terms of absolute amount of overall per capita GDP, but the spatial agglomeration of economic development and economic growth is featured by certain lag in time dimension.

\subsubsection{Evolution of Hotspots in per Capita Growth Index}

Analysis on changes in hotspots and cold spots in per capita growth index of county-scale economy in Guangdong province can be seen from Figure 5. 
Table 1. The Moran's I value of average growth index of per capita GDP in county-scale in Guangdong.

\begin{tabular}{cccc}
\hline Period of Time & $1991-1998$ & $1998-2005$ & $2005-2013$ \\
\hline Moran's I & 0.19100 & 0.24168 & 0.224957 \\
$E(I)$ & -0.011494 & -0.0114944 & -0.01149 \\
$Z(I)$ & 2.853337 & 3.579246 & 3.273854 \\
$P$ & 0.004326 & 0.000345 & 0.001061 \\
\hline
\end{tabular}

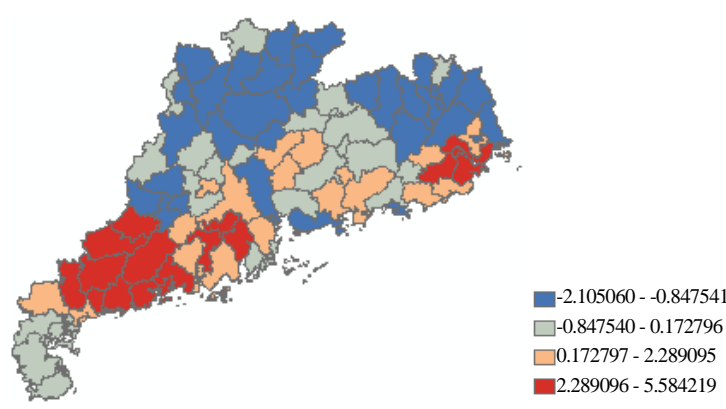

1991-1998

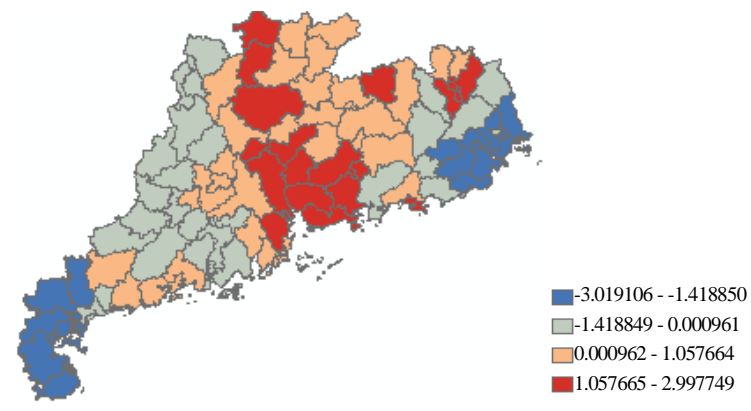

1998-2005

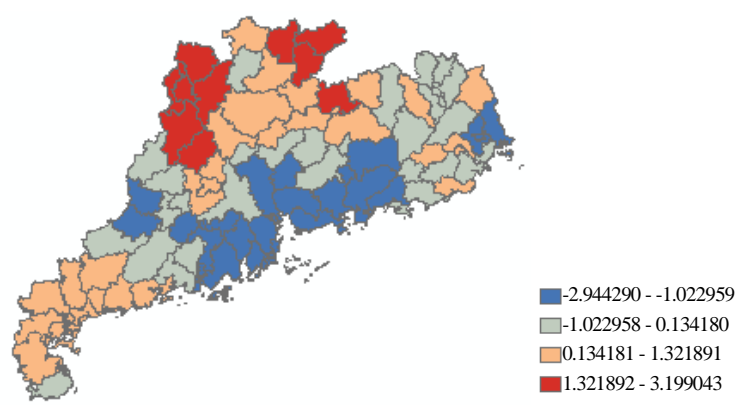

2005-2013

The coldspots of growth $\square$ The secondary coldspots of growth

The coldspots of growth $\square$ The secondary hotspots of growth

Figure 5. Evolution diagram of spatial structure of economic increase in Guangdong province.

As can be seen from the evolution process of the three time periods, hot spots and cold spots areas of countyscale economy in Guangdong are featured by obvious spatial evolution and transition, of which the rotation speed of the hot spots is faster than that in cold spots, and almost none administrative unit is able to remain in the hot zone in the three time periods simultaneously. Namely, greater randomness is manifested mainly in transformation of part of the counties from the northwest Guangdong to the Pearl River Delta and to northern Guangdong. Cold spot area is also featured by strong spatial evolution, and in addition that a few counties in the Pearl River Delta and western Guangdong can maintain some continuity in a short time, the transition has occurred in almost of other areas. Therefore, county-scale economy in Guangdong province has faster transition in areas with high or low rates of economic growth, while geographic concentration phenomenon is relatively unconspicuous.

From the evolutionary process of hot and cold spot areas in three stages, hotspots from 1991 to 1998 are mainly centralized in various counties of Maoming and Yangjiang in western Guangdong and some counties of Yunfu in northern Guangdong. Three counties of municipal districts in Jiangmen, Heshan and Kaiping are in the hot spot zones in the Pearl River Delta region, and there are only municipal district of Shantou, Jiedong and Puning in the east Guangdong region. Corresponding to this is that the cold spot area is mainly concentrated in most counties of Meizhou, Heyuan, Shaoguan and Qingyuan in the northern part of Guangdong, while western Guangdong area, only Yun'an and Yunan of the west of Guangdong in the Pearl River Delta region and city 
area in Guangzhou and two regions in Shenzhen are located in the cold spot area. One possible explanation is that the development northern Guangdong is slower due to the limited economic development in aspects such as resources, capital, transportation caused by getting close to mountain areas. Changes have taken place over time in space in terms of hotspots and coldspots. During 1997-2004, the hot areas are mainly concentrated in the Pearl River Delta and some counties in Shaoguan and Qingyuan of northern Guangdong; the number of cold spots is significantly decreased and they are mainly centralized in some counties of Chaozhou, Jieyang and Shantou in eastern Guangdong and Zhanjiang and Maoming in western Guangdong. During 2005 and 2013, great changes have taken place in hotspots and coldspots once again, and cold hot spots have a banding distribution in the Pearl River Delta and part areas of eastern, western and northwest Guangdong. Among them, the hot spots in this period are mainly concentrated in the most counties of Shaoguan and Qingyuan cities in northern Guangdong; only two area of Huaiji and Guangning in Zhaoqing in the Pearl River Delta are located in hotspots, while the only Lianping city in Heyuan in the eastern Guangdong is evolved from secondary hot spot into a hot spot zone. Cold spot regions are mainly concentrated in the counties of Guangzhou, Shenzhen, Dongguan, Zhongshan, Zhuhai and Huizhou in Pearl River Delta, while others are scatteredly distributed in certain counties of Maoming in western Guangdong and Chaozhou, Shantou, Jieyang and Shanwei in eastern Guangdong'. From the changing process of the above cold and hot spots, it is observed that the pattern of economic growth in the Pearl River Delta is quite different from that in eastern, western and northwest Guangdong.

In addition, the comparison is made between evolution diagram of county-scale economic pattern hotspots in Guangdong province (Figure 4) in four years and evolution diagram of county-scale economic growth hotspots (Figure 5) in three time periods of Guangdong Province. It can be found that: spatial distribution of county-scale economic growth in Guangdong is relatively decentralized, and a larger transition will occur in space over time. For instance, the evolution of the hot zone is from western Guangdong to Pearl River Delta and then to northern Guangdong. Nevertheless, subtle changes in hot spots of county-scale economic structure occur mainly in the Pearl River Delta and its surrounding areas without big transitions. This shows that there is no great relevance between evolution diagram of county-scale economic pattern hotspots in Guangdong province and evolution diagram of county-scale economic growth hotspots, and there are still some differences in their transition behavior, but this has also highlighted that the regional differences have a narrowing trend in Guangdong Province. That is, economic growth hotspots are acting on northern Guangdong with poor county-scale economic development.

\section{Analysis on Spatial Evolution Mechanism of Economic Structure}

Through the analysis of spatial correlation mentioned above, it shows that the per capita GDP of counties in Guangdong province has significant spatial autocorrelation characteristics, but also is featured by local spatial heterogeneity meanwhile. This illustrates that the county-scale economy in Guangdong is not entirely homogeneous in space, and local spatial variability also exists on the basis of certain spatial distribution pattern, and this variability includes two parts of system variability caused by internal factors and random mutation caused by external factors. For analyzing this variation, it is necessary to use theoretical semivariable function models (such as the spherical model, Gaussian model and exponential model) to fit the experimental semivariable function, and the drawn theoretical semivariable function is analyzed. Finally, model with the highest degree of fitting is selected and Kriging interpolation is conducted.

When performing spatial variation analysis, if the use of non-normal data will lead to an increase in the estimated error of variogram, while through statistical description of the datas in four time sections for 88 counties in Guangdong province, it can be found that datas show weak positive-skewed distribution, and datas after logarithmic changes have passed the Kolmogorov-Smirnov test, basically obedient to normal distribution, and the datas as spatial variables for calculating space of variogram are assigned to geometric center of each county-scale spatial unit. Experimental variogram in four years are calculated for model fitting to select models with the best fitting effect, and Kriging interpolation is conducted, and the fitting results are used to calculate the fractal dimension in different directions in four years, and the results are shown in Table 2, Table 3 and Figure 6.

1) Spatial correlation of county-scale economy in Guangdong can be illustrated from the ratio of nugget to sill, and nugget factor from 1991-2013 is firstly decreased and then increased, but $C_{0} / C_{0}+C$ of the four time sections is less than 0.25 , indicating that economic spatial pattern in Guangdong province has a strong spatial 
Table 2. Fitting parameters of variogram of county-scale economy in Guangdong province from 1991 to 2013.

\begin{tabular}{cccccc}
\hline & Parameters & 1991 & 1998 & 2005 & 2013 \\
\hline Range & $A$ & 218,800 & 219,000 & 227,500 & 230,800 \\
Nugget & $C_{0}$ & 0.0603 & 0.029 & 0.049 & 0.0505 \\
Sill & $C_{0}+C$ & 0.3716 & 0.401 & 0.468 & 0.34 \\
Nugget coefficient & $C_{0} / C_{0}+C$ & 0.1622 & 0.03125 & 0.1047 & 0.1485 \\
Fitting model & Model & Spherical & Spherical & Spherical & Spherical \\
Coefficient of determination & $R^{2}$ & 0.646 & 0.755 & 0.831 & 0.908
\end{tabular}

Table 3. Fractal dimensions of variogram of county-scale economic spatial structure in Guangdong province from 1991 to 2013.

\begin{tabular}{cccccccccc}
\hline Parameters & \multicolumn{2}{c}{ Omni-Directions } & \multicolumn{2}{c}{ South-North } & \multicolumn{2}{c}{ Northeast-Southwest } & \multicolumn{2}{c}{ East-West } & Southeast-Northwest \\
\hline Year & $D$ & $R^{2}$ & $D$ & $R^{2}$ & $D$ & $R^{2}$ & $D$ & $R^{2}$ & $D R^{2}$ \\
1991 & 1.827 & 0.502 & 1.818 & 0.599 & 1.851 & 0.419 & 1.921 & 0.010 & 1.9880 .001 \\
1998 & 1.779 & 0.635 & 1.827 & 0.647 & 1.729 & 0.784 & 1.770 & 0.309 & 1.9520 .013 \\
2005 & 1.785 & 0.708 & 1.814 & 0.698 & 1.783 & 0.827 & 1.801 & 0.355 & 1.9370 .021 \\
2013 & 1.793 & 0.786 & 1.789 & 0.746 & 1.820 & 0.816 & 1.909 & 0.115 & 1.9730 .005 \\
\hline
\end{tabular}

correlation, and its spatial variability is affected by both structural factor and random factors. The degree of variation caused by random factors can be seen from the nugget value, showing a narrowing trend in 1998, then gradually increased, but the proportion of the variation degree caused by it to the total variation is always less than $10 \%$, while the proportion of structural variation is always greater than $90 \%$, indicating that in the spatial pattern evolution of Guangdong province, the evolutionary differentiation of county-scale pattern caused by spatial auto-correlative structural factors is greater than the variation caused by random factors such as data variation and others. It can be seen from the nugget with four time sections, and structural differentiation of this spatial pattern is also firstly increased and then decreased.

2) As can be seen from Table 2, the range scale of county-scale development in four years under the given step-length is greater, which means that the spatial correlation of county-scale economic development in Guangdong province is gradually reduced with the increasing distance between the counties, but when increased to range $A$, it is then basically stabilized and has no further increase, and spatial correlation disappears. Based on temporal dynamics in four year, the range of county units from 1991 to 2013 is gradually increased, which suggests that actuating range of spatial correlation effect caused by structural spatial gradient of economic development of county scale is gradually increased, and that is, economic growth is gradually moving away from the polar nuclei, and the degree of spatial agglomeration has dispersed. Seen from the model chosen for fitting, space fitting model selected by the least squares method in four years is all spherical model (Spherical), which shows that county-scale economic spatial structure in Guangdong has good stability and continuity. The determination coefficient of the model indicates the results of model fitting, and the determination coefficient $\mathrm{R}^{2}$ of model in four years is gradually increased, indicating that spatial self-organization of county-scale economic development in Guangdong province is growing.

3) As can be seen from the fractal dimension values in Table 3, the fractal dimension in four years has experienced the process from getting small to big in all directions except south-north, indicating that spatial differences in county-scale economy of Guangdong show a trend of progressively smaller after 1998. From all directions of regions, the value in east-west and southeast-northwest direction is relatively large, indicating that economic space in eastern and western regions of Guangdong province have small differences, but the fitting degree is generally not high; the value in the south-north direction gradually becomes smaller from 1991, suggesting that spatial variation in economy in Shaoguan and Qingyuan region in northern Guangdong and in cities such as Guangzhou, Zhongshan, Shenzhen, Dongguan, Foshan and Zhuhai in the Pearl River Delta is gradually greater. 

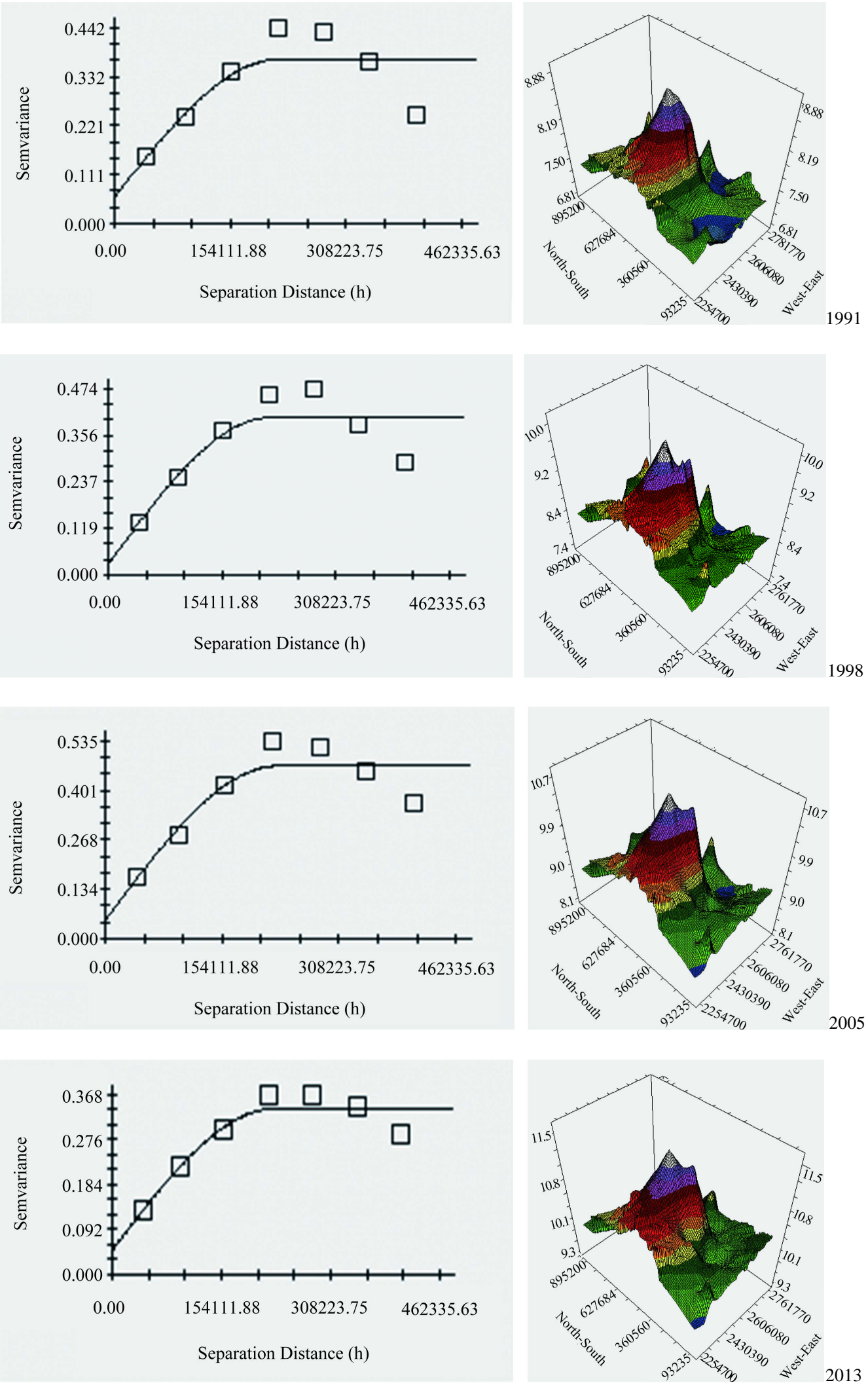

Figure 6. Evolution diagram of spatial pattern variation of county-scale weconomy in Guangdong province (left: synthetic variance fitting figure; right: Kriging 3D image). 
4) As can be seen from 3D map of Kriging in Figure 6, economic pattern in Guangdong province have shown great similarity in four years, taking on slope line structure with central part as vertex and dispersing from three directions of east, west and north, and southwest and southeast regions far away from the vertex show plain structure. In the evolution of the economic structure, the single structure in the middle is gradually evolved into double vertex structure. The closer to the central region it is, the faster the uplifting speed will be. This suggests that in the process of economic development in Guangdong province, the Pearl River Delta region has been in a "leader" status with rapid economic development, while in the eastern, western and northern Guangdong areas, they have been relatively backward with greater spatial difference in economy, but also there is diminishing trend.

\section{The Driving Factors on the Evolution of Spatial Pattern}

\subsection{The Basic Differences in Natural Condition}

Natural and geographical condition is one of the important factors of economic development. Most cities of the Pearl River Delta are located in the south of the Tropic of Cancer, which makes it has the advantageous natural conditions. And large alluvial plain located in the Pearl River Estuary with convenient sea, road and air transportation. While in the eastern, western and north Guangdong, most of the areas are made up of mountains and rolling hills, complex geographical environment makes poor traffic conditions, and the economy of these areas are based on agriculture over the long term. Poor efficiency of agricultural products and underdeveloped commodity economy lead to the backward economy.

\subsection{The Factors of Location}

The regional economic disparities between the Pearl River Delta and the eastern, western and north Guangdong performed by spatial pattern of economic development in Guangdong Province are concerned with the locations. Since the reform and opening-up policy, benefited from the potential location advantages of its proximity to Hong Kong and Macao, the Pearl River Delta has attracted large numbers of talents, capital and technology, and taken full advantage of its privileged location, and the economy has developed rapidly, which became one of the three major economically developed regions of the country. With their own characteristics and advantages, the coastal regions of Eastern and Western Guangdong has taken full advantage of the special policies for the economic zones and coastal open cities, and made significant development, such as light industry and commercial trade in the east, Petrochemical Technology and processing industry in the west. But due to far away from Hong Kong and Macao and poor traffic, the Eastern and Western Guangdong are significant differences in their levels of development from Pearl River Delta. Whereas, because of the location factors such as located in the mainland and complex area, the mountainous region in the north Guangdong is in a state of relatively backward technology and lack of funds, which leads to slow development, and has Significant differences with the Pearl River Delta.

\subsection{The Policy of Regional Development}

Since the implementation of the reform and opening-up Policy, benefited from the potential location advantages of its proximity to Hong Kong and Macao, the Pearl River Delta takes the leader to reform and open, and accompanied by the implementation of strategies for the unbalanced conditions and preferential policies as following, the talents, capital and technology incessantly flowed into the Pearl River Delta. Moreover, with fewer outlying areas of linkage, the development of the Pearl River Delta and the surrounding areas are uncoordinated, the whole of Guangdong Province forms four major economic regions. In the four major economic regions, there were significant differences. In recent years, especially after the year of 2000, Guangdong has promulgated a series of policy formulation to promote harmonious development of regional economy. These policies involved a wide range of the two flanks and north area of Guangdong Province, and they emphasized the coordinated development between regions.

\section{Conclusions}

The per capita GDP of county-scale in Guangdong province as the index, through Exploratory spatial data anal- 
ysis(ESDA), it selects Global Moran's I and Getis-Ord $\mathrm{Gi}^{*}$, average growth index and semivariable function as measure index, based on the time quantum from 1991 to 2013 to analyze Global spatial correlation and its developed trend for more than 20 years of Guangdong province, and selects 1991, 1998, 2005 and 2013 as the time section, describing economic spatial evolution of four regions of Guangdong province and the driving force factors in four time quantum. Through the analysis, a certain regularity is found in county region of Guangdong province: 1) On the overall spatial pattern of economy, the economy development of county region in Guangdong province presents a strong spatial correlation, namely the region with similar economic development level is aggregate distribution in the space, but its aggregate trend falls in 2004, then gradually increases and maintains a stable posture. Economic hot spots are mainly shown in circle-layer spatial structure with Guangzhou, Shenzhen, Zhuhai, Foshan, Zhongshan and Dongguan of the pearl river delta as the center, and there are no big changes in four time cross sections; while the cold spots are mainly distributed in Qingyuan, Yunfu, Heyuan, Meizhou and Shaoguan of mountain areas of North Guangdong, parts of the counties in North Guangdong Jieyang, west Guangdong Zhanjiang have entered in different periods. 2) On spatial pattern of economic growth, coldspots and hotspots also present block structure, but the developing situation shows more randomness and instability of structure in the space. Hot and cold spots are switched frequently. There is no obvious geographic concentration. 3) On the evolution mechanism of economic spatial pattern, the economy of county in Guangdong province has strong correlation, and spatial variation caused by the structural factors of spatial autocorrelation accounts for a bigger proportion, and self-organization of spatial economic development is becoming more and more strong; while the homogeneity of all-dimension presents a trend of decrease first and then increase, it is still in the trend of decrease with comparing. Looking from all dimensions, the heterogeneities of the economic development of both northeast to southwest and east to west are relatively best, with smaller spatial differences. 4) There are many driving factors on evolution of spatial pattern. This paper mainly makes analysis on three aspects as the natural condition, geographical condition and the regional economic policy. Natural condition and geographical condition as the foundational factors and intrinsic motivation for the development of the four regions of Guangdong province have certain influence on evolution of the economic pattern of the pearl river delta and east, north and west regions of Guangdong; and as extrinsic driving force of regional development, regional policy also has a great effect on its evolution of pattern.

\section{References}

[1] Rozelle, S. (1991) Rural Industrialization and Increasing Inequality: Emerging Patterns in Chinas’ Reforming Economy. Economic Development and Cultural Change, 39, 471-506.

[2] Max, L. and Wang, E.R. (2002) Forging Ahead and Falling Behind: Changing Regional Inequalities in Post-Reform China. Growth and Change, 33, 42-71. http://dx.doi.org/10.1111/0017-4815.00179

[3] Xu, J.H. and Lu, F. (2005) Spatial and Temporal Scale Analysis on the Regional Economic Disparities in China. Geophysical Research, 1, 57-68.

[4] Zhang, Y. (2010) The Analysis on Economic Difference of Chinese County. Chinese Rural Economy, No. 11, 15-25.

[5] Wang, Y. and Xiao, H.S. (2011) Research on the Economic Growth Inequality and Dynamic Convergence of Counties in Yangtze Delta. East China Economic Management, 25, 41-69.

[6] Gin, C. and Lu, Y.Q. (2009) Evolvement of Spatial Pattern of Economy in Jiangsu Province at County Level. Geography Journal, 64, 713-724.

[7] Meng, D.Y. and Lu, Y.Q. (2011) Industry Decomposition of County Economic Disparity Based on Gini Coefficient in Henan Province. Economic Geography, 31, 799-804.

[8] Ouyang, N.J. (1993) Economic Restructuring and Regional Disparities in Guangdong Province. Geography Journal, 48, 204-217.

[9] Ding, S. and Li, H. (2012) Spatial-Temporal Analysis on Economic Disparities of Developed Province at County Level: The Case of Guangdong Province. Chinese Regional Economy, No. 3, 11 p.

[10] Zhang, S.L. and Zhang, K. (2007) Comparison between General Moran’s Index and Getis-Ord General G of Spatial Autocorrelation. Journal of Sun Yat-sen University, 46, 93-97.

[11] Getis, A. and Ord, J.K. (1992) The Analysis of Spatial Association by Use of Distance Statistics. Geographical Analysis, 24, 189-206.

[12] Fang, Y.L., Huang, Z.F. (2013) Research of Spatial Differences of County Economy in Anhui Based on Geostatistical Analysis. Economic Geography, 33, 33-38. 
[13] Sui, Y.Y., Du, F. and Zhang, X.C. (2011) Spatial Heterogeneity of Available Soil Nutrients in Abandoned Ole-Field Communities in the Loess Hilly Region. Acta Pratacultural Science, 20, 76-84.

[14] Gin, C. and Lu, Y.Q. (2011) Evolvement of Economic Development Diversity in the Changjiang River Delta Based on Spatial Variogram. Geographic Science, 31, 1329-1334. 